\title{
Autonomy, Technology, and Language-Learning in a Sheltered ESL Immersion Program
}

Garold L. Murray

This article reports on a classroom-based research project exploring the learning experiences of 30 Japanese English-as-a-second-language (ESL) exchange students in an environment highlighting learner autonomy and the use of technology. It first addresses a growing concern among practitioners, that is, how to create a learning environment that facilitates learner autonomy. One possible answer is a learning structure that first requires students to reflect on their second-language needs and interests. They then set their learning goals, devise projects to help meet these goals, and self-assess their learning. This model was implemented in three multimedia lab classes of two content-based language courses of a sheltered immersion program. The students' learning experiences are examined in a multiple case study relying on data collected through questionnaires and interviews, as well as participants' learning logs, teacher observation, and measures of academic achievement. The data suggest that promoting learner autonomy through experiential learning enhances motivation, metacognitive knowledge, and personal growth. The article concludes by exploring possibilities for the application of this model in regular ESL classrooms.

The notions of autonomy and self-direction have been the subject of intense debate and a burgeoning body of research since the end of World War II (Gremmo \& Riley, 1995). Gradually, these ideas are edging their way into mainstream educational practice. Educators, specifically teachers, often confined by the requirements of the system and the expectations of society, are left to ponder the question of "how might the classroom be transformed into a learning environment that facilitates the promotion of autonomy?" (Ho \& Crookall, 1995). Answers to this question are complicated by emerging educational technologies and the phenomenon of internationalism.

The availability of educational technology makes it increasingly feasible to individualize and personalize the instructional process. Yet, as many of us have witnessed, "there is a strong and repeated tendency for the introduction of some new technology by enthusiastic 'technicians' to be accompanied by a retrograde and unreflecting pedagogy" (Gremmo \& Riley, 1995). Our question might then be rephrased more precisely to read "how might generally available technologies be used to transform the classroom into a learning environment that facilitates the promotion of learner autonomy?" 
The rising tide of internationalism coupled with the commercialization of language-learning has enticed an increasing number of overseas students to our classrooms. How might this reality inform a model promoting learner autonomy through the use of technology? Gremmo and Riley (1995) call for research into autonomy and self-direction that takes into account "cultural variation in learning attitudes, roles and activities" (p. 151). International students accustomed to more traditional learning environments would not be prepared for classes organized according to the premises of autonomy and self-direction (Cotterall, 1995). Similarly, they may not be accustomed to using computers and information technology in the classroom. How might they react to a learning structure promoting autonomy through the use of technology? To explore these questions, this research project examines the experiences of 30 Japanese exchange students in three multimedia lab classes of two content-based courses of an ESL sheltered immersion program.

This particular program, at the University of British Columbia, receives nearly 100 third-year students from Ritsumeikan University in Japan each academic year, that is, for an eight-month period. Although these students, whose first language is Japanese, are offered a full complement of courses especially designed for them, they are also encouraged to take regular courses depending on their level of English, which in this case ranged from low to high intermediate, according to their entry TOEFL scores. In addition to content-based sheltered courses, the program provides housing with English-speaking roommates as well as a variety of cultural and social activities.

This study focuses on three multimedia lab classes that-along with a large group lecture and tutorials-were components of two sociology courses especially designed for these students. The lab classes were structured according to principles of autonomous language-learning; that is to say, learners had the opportunity to assume a degree of control over their learning while accepting the corresponding responsibility (Holec, 1981). Of the 60 students in these classes, 30 volunteered to participate in the study. In this article their experiences are discussed in the context of three widely made claims, that is, that learner autonomy increases motivation, encourages the acquisition of metacognitive knowledge and skills, and facilitates personal growth. In addition, the article explores the students' reactions to the model, or learning structure, and discusses its general classroom application.

\section{Conceptual Framework}

The learning structure implemented in this study attempts to account for the three essential components of learner autonomy: structure, control, and responsibility. As Holec (1981) writes, "there must be a learning structure in which control over the learning can be exercised by the learner, that is, in which the learner has the possibility of exercising his ability to take control 
(p. 7). Holec defines control over the learning to include responsibility for determining the objectives, defining the contents and progressions, selecting methods and techniques, monitoring the procedure of acquisition, and evaluating what has been acquired. In short, learners must be operating in a structure that enables them to exercise control over their learning and to assume the responsibility this entails.

A review of the literature suggests several characteristics of such a structure. An emphasis on learning translates into an active use and exploration of the second language (Holec, 1981; Little, 1990, 1995). Project work is one way to realize this requirement (Kenny, 1993a, 1993b; Little, 1995). Learners must have direct contact with the target language through a wide choice of media and materials (Holec 1981, 1987; Little, 1990, 1991; Littlewood, 1993; Forsyth, 1990, 1993, 1994). Learners manage their learning (Holec, 1981, 1987; Forsyth, 1993). This implies that learning is individualized and personalized. In other words, learners determine their own pace and make choices based on their personal needs, learning styles, and interests (Holec, 1981; Dickinson, 1987). There is a shift in emphasis from teaching the language directly to helping individual learners learn how to learn the language (Holec, 1981; Dickinson, 1987; Hoven 1992). Teachers then have the responsibility of providing contextualized learner training; in other words, learners should be taught the necessary strategies as they relate to a specific task (Wenden, 1995). Learners have the responsibility of monitoring and assessing their learning (Holec 1981; Dickinson, 1987, 1993; Gremmo \& Riley, 1995; Forsyth, 1993; Kenny, 1993a). The language-learning environment must be based on a structure that brings learners into contact with the target language while providing them with sufficient choices to enable them to assume ownership of their learning. These characteristics underlie the learning structure implemented in this study.

\section{Structure of the Class}

As Figure 1 illustrates, the learning structure begins with the learners' needs and interests. As a first step, learners set goals based on their needs and interests. They then designed projects, including investigative reports, aimed at helping them meet these goals. In addition, they assessed their own projects and learning. For most of these students, the combined concepts of goal-setting, self-assessment, and choice created a style of class new to them.

To assist them in the goal-setting process, students were asked to think about a set of questions. They were told that to set their goals, essentially all they had to do was ask themselves the question: What do I want/need to learn? This question was broken down into three more specific ones: (a) What language skills do I want/need to improve? (b) What content topics do I want/need to explore in greater depth or learn more about? and (c) What 


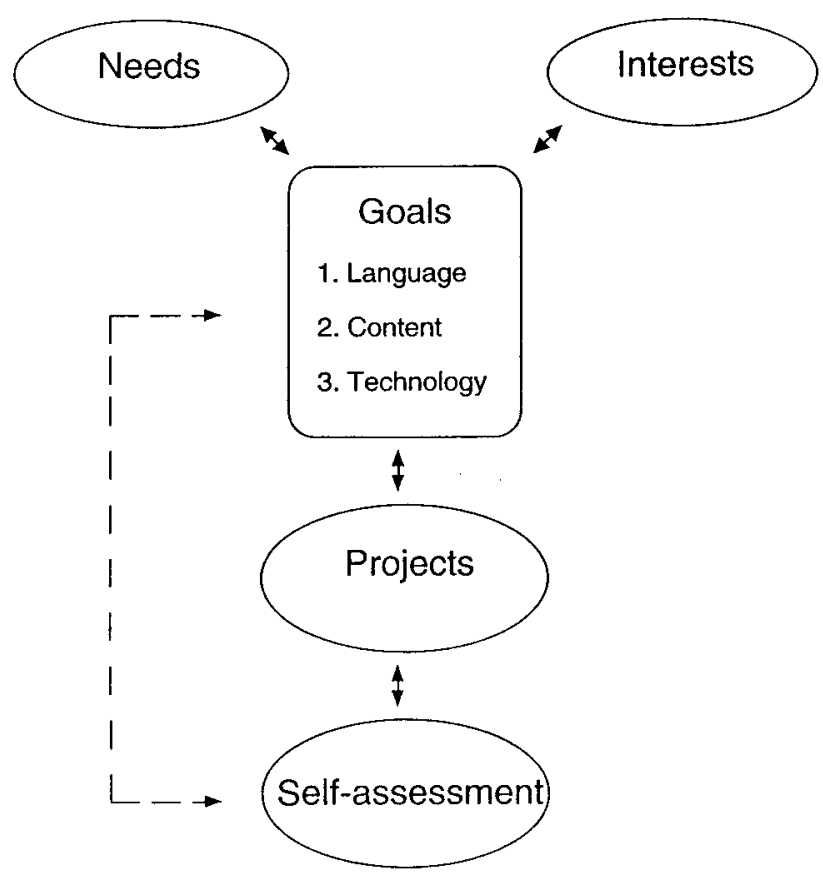

Figure 1. A learning structure in support of autonomy.

technological skills do I want/need to develop? The answers to these questions were their language, content, and technology goals, listed in Figure 1.

The students were then given the task of designing projects that would help them meet these goals. They could work alone or in small groups. The topics and the form the projects took were of their choosing. It should be noted that the general content areas of the two courses-a look at the host city and province through a wide-angle sociological lens and an examination of the Canadian educational system emphasizing multiculturalism and intercultural communication-were determined by the course syllabus. However, the subject areas yielded a wide enough array of topics to satisfy the curiosity and diverse interests of these newly arrived students eager to learn about their new home.

The organization of the classes, which met once a week for one and a half hours, was based on the completion of two projects each semester. The students decided what they wanted to do in each class. At the beginning of an assignment, they brainstormed for a topic and suitable project. To get ideas, they browsed the World Wide Web and the collection of books, magazines, and videocassettes available in the lab. Later, they used these same resources along with outside sources to research their topics. In the 
preparation stage, the students had access to video equipment, a scanner, and graphics and word-processing programs. In the final stage, they generally presented their projects to the class.

Evaluation procedures were based on peer and self-assessment. The students downloaded blank assessment checklist forms from a Common File on the Server. ${ }^{1}$ Although they were encouraged to develop their own assessment criteria, lists of suggested criteria were also available in the common file. In the beginning, most students simply chose criteria from these lists in order to complete their assessment forms. Gradually, they modified these suggestions to suit their specific projects until they were at least developing some of their own assessment criteria. As the arrow in Figure 1 suggests, the assessment criteria had to reflect the learners' initial goals. When the project was completed, they rated their own work and that of their peers according to these criteria on a scale of 1 to 5 .

Another important aspect of the assessment process was for the students to keep learning logs where they were asked to document their learning. As well as keeping a record of what they did in and outside of class, the students were encouraged to reflect on their learning and how they learned. At the end of each semester, the students assessed their learning logs through suggested and individual criteria as described above.

As the teacher, I adopted the role of counselor (Gremmo \& Riley, 1995) whose chief responsibilities were to "help learners develop their learning competence" and to "set about creating the material conditions favorable to language learning" (p. 159). More specifically, I structured the learning environment, ensured that appropriate resources were available, helped learners access outside resources, offered guidance to individuals or small groups, and modeled the use of technology. In addition, I guided learners through the processes of goal-setting and self-assessment.

\section{The Study}

The purpose of the study was to explore the experiences of the exchange students as they operated in this particular learning structure. Thirty, or approximately one half of the students in the three lab classes, volunteered to participate. ${ }^{2}$ The project began with the following focus questions: (a) What is the experience of the Japanese students as they learn English in this particular learning structure designed to promote learner autonomy? (b) What effect might this experience have on their ESL acquisition? and (c) What possible implications might this information have for second-language pedagogy? To investigate these questions, the study employed a case study design (Stake, 1995; Yin, 1994).

Data collection, which took place over the course of one academic year, relied on a variety of methods and procedures. Near the end of both the first and second terms, participants completed questionnaires. Each question- 
naire was different with approximately 25 Likert scale items as well as several open-ended response questions. ${ }^{3}$ Learning logs, projects, and self-assessment checklists were collected. Videotaped interviews were conducted with eight participants randomly selected as a focus group. ${ }^{4}$ As the instructor, I recorded my observations in journal entries made immediately following the classes. Data also included pre-/posttest measures of achievement that were part of the program.

In the initial phase of data analysis, Likert scale items were grouped thematically into such categories as goals, planning, choice, self-assessment, metacognition, motivation, and so forth. Although the labels represent concepts that appear frequently in the literature on autonomy and self-direction, most of them originated from responses to open-ended questions on the questionnaires as well as in learning log entries. For example, when students' referred to goals, choice, or decision-making, these words were used to code the text. The responses to the Likert scale items were then correlated with the responses to other items in their category. The questionnaire results were triangulated with information from the learning logs, videotaped interviews, and my observations.

\section{Findings and Discussion}

The three questions guiding the research focused on the learners' experiences as they worked in this particular classroom model promoting learner autonomy. The literature would suggest that these learners should be experiencing enhanced motivation, metacognitive knowledge (i.e., as well as learning the language, they should be learning how to learn the language), and personal growth. Therefore, three questions are asked of the data: (a) Is there any evidence to suggest that autonomy is a source of motivation for these students? (b) What evidence is there to indicate that the students were actually learning how to learn the language (metacognition)? and (c) What evidence is there that autonomy facilitates personal growth?

\section{Motivation}

A common claim made for autonomy is that it increases learner motivation (Knowles, 1975; Holec, 1981; Dickinson, 1987, 1995). Underlying this claim is the assumption that having opportunities to make choices or decisions regarding one's own learning, that is, having control of the process, can foster intrinsic motivation (Deci \& Ryan, 1985). After three months of working in this learning structure, participants' responses on the questionnaire indicated their sense of control. When asked, "What did you like best about this lab class?" $40 \%$ of the respondents commented on freedom of choice, the pursuit of personal interests, and/or decision-making. Many of the comments were succinct, for example, "I can decide what to do, according to my interest" (1.Q33.10). ${ }^{5}$ However, some students made connections between 
the elements of choice, decision-making, and responsibility. As one student wrote, "In that lab class, I could think what I would do by myself. This means I had more responsibility for myself than any other classes. I like this point" (1.Q33.12). This student relates the control she experienced to the responsibility she felt for her learning. Taking responsibility for learning is seen to be one of the key indicators of intrinsic motivation (Dickinson, 1995).

Another participant, Emiko, ${ }^{6}$ although enthusiastic about the control she had over her learning, notes that the responsibilities this entails can present challenges.

I wasn't used to this style of learning, so it was a little hard for me to decide what I wanted to learn and what I did to achieve my goals at first. However, once I got used to it, I really like this class because I can learn what I want to learn, especially that decision making is students' job. (1.Q33.11)

Although Emiko's challenge was to set her goals and to devise the means to meet these goals, she experienced a degree of control that gave her a sense of satisfaction.

The time and effort Emiko and her fellow group members put into their projects are strong indicators of their motivation. In Emiko's case her main language goal was to improve her oral fluency, whereas her technology goals were to learn more about the computer and video technology. To meet the content goal of exploring multiculturalism in the local area, Emiko and her group members combined it with their other common goals by producing a short video documentary based on interviews they conducted with young English-speaking Canadians, exploring their motivation to learn Japanese at a heritage school. The hours these students spent-creating a list of interview questions, organizing the interviews, not to mention conducting them, and editing the video footage into a seven-minute film-provide a clear indicator of the intrinsic motivation they were experiencing.

In general, the learning logs and the projects themselves provided evidence of the time and effort the students put into their work. Obviously, some goals required more than others. For most of the students, improving speaking fluency was the prime language goal. It did not take them long to discover that in a self-instructional environment, speaking practice can be "the toughest nut to crack" (Jones, 1993, p. 455). Therefore, the challenge after they had decided on their topic was to find ways of carrying out the project that would help them achieve their language goals. Their curiosity about their new environment coupled with their desire to meet Canadians encouraged them seek solutions beyond the walls of the multimedia lab. Therefore, after initially researching their topic through Netscape, many of the students employed ethnographic methods, for example, interviews and direct observation, which offered them ample opportunity to practice their 
oral skills. The hours and effort that went into these projects are a testimony to their motivation.

When asked on the second questionnaire to rate the statement, "Being able to learn what I wanted to learn motivated me to do good work," $85 \%$ of the respondents agreed or strongly agreed. Yet a learning environment that supports autonomy does not magically motivate all learners. One student reported a lack of motivation in spite of being able to study what interested him, "This class was boring for me. Even though I could choose my topic, I chose the topic which was easy to accomplish the project (not what I really wanted to study)" (2.Q36.13). He was obviously prepared to invest only a minimal amount of time and effort. His goals were based more on expediency than on his desire to learn about something that interested him. Another participant wrote, "You must have motivation to study or learn something in this class" (2.Q37.10). These comments suggest that the desire to learn is a factor powerful enough to offset the motivational potential of control over the learning process. This study suggests that although autonomy may enhance satisfaction with the language-learning task and enable learners to experience a degree of control over the learning process, it does not necessarily foster, much less provide, a desire to learn. The desire to learn emerges as a strong determinant of learners' choices.

Closely linked to the desire to learn is the process of goal-setting. Research has shown that students who set specific and challenging goals for themselves devote more time and effort to a task than those who do not (Tremblay \& Gardner, 1995). Certainly groups like Emiko's, which had specific and challenging goals, expended a great deal of time. The data suggest that the students' sense of responsibility was enhanced by goal-setting. The process of relating learning to personal needs and interests and then reformulating these in terms of goals seems to have reinforced the students' sense of ownership and responsibility for their learning. Goal-setting combined with control over the process leading to the realization of the goals appears to have had a positive effect on the motivation of most students.

\section{Metacognition}

A frequently cited justification for the promotion of autonomy is that students learn how to learn the language, which prepares them to continue learning beyond the period of formal instruction. Teachers must help them acquire the knowledge and strategies they will need in order to do this, that is, provide learner training (Victori \& Lockhart, 1995). In accordance with the advice of Holec (1981) and Wenden (1995), in this study the objectives of learning a language and learning how to learn a language were pursued together; that is, learner training was offered in the context of the task at 
hand. This section examines the participants' experience from the standpoint of learning how to learn.

Likert scale items on the questionnaires completed at the end of both semesters offer a general view of the participants' experience in the area of metacognition. On the second questionnaire, when the participants were asked to respond to the item "This class helped me see how I can learn English by myself," $15 \%$ strongly agreed and 54\% agreed, whereas $15 \%$ disagreed and $15 \%$ had no opinion. On both questionnaires, most of the participants $(80 \%)$ agreed with the statement "I set meaningful and realistic goals for myself." Moreover, most indicated that they planned projects that helped them meet these goals. Given the complexities to be dealt with in setting goals and successfully matching learning activities to these goals, it appears that the participants were gaining metacognitive knowledge and putting it to good use.

A comparison of the participants' goals set at the beginning of September with those set in January supports this claim. In September, when asked to state her language goals, Mayumi wrote, "I want to improve all of the language skills, especially reading, writing, and speaking. However, I don't know how to improve my speaking skills, so please give me the advice" (L1.13). In January, outlining her language goals for the second term, Mayumi writes, "I want to improve all skills of English. So I want to make more friends and talk, or to go to the library and read some English book, or watch TV and listen to the radio. I know this is not easy thing to do, but I try to do these things as much as possible" (L1.13). Mayumi now understands that she can improve her language skills by using them to perform real-life tasks.

Other participants demonstrated changes in their metacognitive knowledge in an open-ended question on the first questionnaire. They were asked (a) what they thought was the best way to learn a language before they came to Canada and (b) what they thought after three months in the program. Emiko's response, for example, shows how her thinking shifted from a relatively passive to an active approach. When she came to Canada, she thought she would "automatically learn the language" by being immersed in the environment. Now she realizes this is not enough. She says, "I need to do something in English, try to use English as much as I can" (1.Q40.11). Tomoko, who expresses similar thoughts, concludes by saying, "I have to speak, ask, practice, and communicate with [English speakers]" (1.Q40.19). Both Emiko and Tomoko demonstrate a much clearer understanding of what they must do to learn the language. Like Mayumi, they see the need for a more active approach in which it is their responsibility to take the initiative.

Learning log entries also indicate students were learning how to learn the language. The entries attested to the kinds of skills they were acquiring and suggested increasing insight into the cognitive processes involved in com- 
munication, success in designing projects to meet goals, and ability to assess progress. Other comments emphasized the degree to which participants enjoyed their work and the opportunity to make friends through collaborative efforts, suggesting something more than the potential for enhanced motivation and the expansion of metacognitive knowledge. These comments hint at the potential of autonomy combined with experiential learning to provide opportunities for personal growth.

\section{Personal Growth}

Another claim made for autonomy is that it promotes personal growth on the part of learners. Because of their potential to personalize the learning process and foster critical thinking, Kenny (1993a) concludes-after five years of experimentation - that combining experiential learning with autonomy offers second-language learners a vehicle for the exploration of their self-concept and its expression. Commenting on one area of growth essential to second-language development, Dickinson (1987) claims that autonomy can help reduce learners' inhibitions and build self-confidence. Developing learner autonomy in the classroom in relation to pedagogical tasks reinforces learners' confidence to use the target language in real-life situations. In other words, pedagogical autonomy leads to communicative autonomy (Little, 1995).

Learners' comments in this study lend credence to this argument. Emiko relates how doing the projects helped her confront her anxiety about talking on the telephone: "I had to make a lot of phone calls to research my topic, and now I'm fine making calls. This class pushed me a little to overcome my fear" (1.Q36.11). The class provided her with the opportunity and the purpose to practice this skill, or set of skills, in a real-life context, which helped her face her inhibitions and gain self-confidence.

Emiko's experience is not unique. Tomoko, for instance, relates how the instructor's feedback concerning her progress gave her "confidence to speak English more often" (B.19). She elaborates on how the lab class and other courses in the program encouraged her to think critically and voice her opinions, in spite of being "a little bit shy":

[In Japan] I just sat down quietly, took notes, listened to lectures, and memorized what I needed for examinations. I did not have questions and my own opinion. I did not have any class discussion. Now, after I came to Canada, I have changed. I always try to have my opinions toward our topics, and to say something. (B.19)

Tomoko attributes these changes to instructors' allotting time to think about topics and their expectations that students express their opinions in class and on assignments. She concludes her reflections on her cultural 
immersion experience by writing, "I think that this studying abroad is not the end of my dream [to live abroad] but the start of my new self."

Other participants' reflections offer more direct support for Kenny's claim that promoting autonomy through experiential learning leads to personal growth. For example, in her final journal entry one student remarked, "Through the three projects, I learned many things. I could consider from many points of view. To observe many things and to contrast many things among culture, I grow up myself. I absorb everything" (L1.6). This student has made a connection between personal growth, exploratory learning, and cultural immersion. This study can make no hard claims concerning the degree to which autonomy influenced the experience of these students in view of the many factors at work in their environment. Yet the data suggest that personal growth can be enhanced in cultural immersion programs by promoting learner autonomy in conjunction with experiential learning.

\section{Suggestions for Classroom Application}

Given the specific circumstances in which this model was implemented, it is necessary to address the issue of classroom application. Not every teacher has the resources of a multimedia lab at his or her disposal; however, this model can be incorporated in other educational environments. Although the model was implemented in its entirety at one point in time in this experimental setting, teachers must be reminded that learner autonomy is a long-term goal that can be worked toward gradually.

A prime concern for teachers is how well will this innovation work with my students at their current level of proficiency? In this study the model appeared to work with learners at the intermediate level. It is probably appropriate for more advanced learners as well. At first glance, given the language skills required to do project work and investigative reporting, it would appear to be inappropriate for beginners. However, this is not necessarily the case.

Projects can take many forms, for example, posters, brochures, pictorial essays, and be adapted to suit the learners' language level. For example, Dam (1995), who has worked extensively with beginners, has her students find words in a picture dictionary that they would like to remember and to draw pictures of these words. As a companion activity, Dam's look for pictures or draw at least five things for which they know the word or would like to know the word. These are ideas for simple projects that ground the learning in the students' needs and interests while providing teaching opportunities. Similarly, a presentation does not have to be a formal affair. Sharing one's work with classmates in a small group is a form of presentation. Nor does assessment have to be a complicated, mysterious process. All learners, including beginners, can keep records-in the form of learning logs or checklists-of what they did inside and outside of the classroom. Students can 
become accustomed to reflecting on their work through class discussions focusing on such questions as "What did I learn here?" or "If I had this to do over again, what might I do differently?" With proper guidance, even beginners are capable of setting goals, making decisions about content and methods, and assessing their progress.

Offering guidance to learners becomes a key task for teachers. In a classroom that fosters learner autonomy, the teacher is often hard to spot, because he or she is always on the move among groups, consulting with learners, offering advice or guidance. Yet the teacher's prime responsibility is to incorporate into the learning environment opportunities for the students to assume control and responsibility for their learning. In doing so, teachers must be mindful of cultural differences. Asian students expect their teacher "to exercise authority, that is, to look after or nurture her students and take charge" (Ho \& Crookall, 1995, p. 238). The challenge is to gain the students' respect and trust by developing a learning structure that offers them the security of clearly spelled-out expectations and continuous support and guidance as they grapple with the demands of "a new style of learning." In this study "scaffolding," which was gradually withdrawn as learners become more autonomous (Galloway \& Labarca, 1990), was useful to help learners set goals and assess their own their work. In addition, teachers have to model the skills they want their students to develop, for example, planning strategies, presenting, assessing. I actually do a project, present it, and have the class assess it. One of the most important topics the teacher can model is talk about learning. Through discussions with the whole class, small groups, and individuals, the teacher can create an environment where it is common to reflect on what is being learned, how it is being learned, and how procedures might be improved. Finally, teachers need to remember that learner autonomy is a long-term goal that students and teachers gradually work toward together. However, it is teachers who provide opportunities for its development in how they structure the learning environment.

\section{Conclusion}

Motivation, metacognition, and personal growth were strong elements in the experience of these students as they learned English in this particular learning structure designed to promote learner autonomy. The data suggest these elements are closely interrelated. Future research might explore how they are connected and how one might influence the other. This study also suggests that the notion desire to learn as a component of motivation requires exploration. Whereas work on autonomy often presupposes a desire to learn, future research might explore this nebulous construct and its relationship to learner autonomy. Furthermore, as learner autonomy gains widespread acceptance as an educational goal, there is a pressing need for classroom-based research offering teachers insights into a variety of models fostering learner auton- 
omy as well as concrete suggestions for their implementation (for an example, see Dam, 1997).

Overall, the learners in this study seemed to respond positively to this particular model. On the questionnaires completed at the end of the first and second semesters, they were asked to rate on the Likert scale the item "I enjoyed this class." In each case, at least $80 \%$ of the participants agreed or strongly agreed, whereas approximately $10 \%$ disagreed and $10 \%$ indicated no opinion. Open-ended questions indicated that they took satisfaction in pursuing their own interests, having freedom of choice, learning about computers and the Internet, making their own decisions, and collaborating with friends. Yet this meant acquiring a host of metacognitive strategies and modifying their perceptions and beliefs about language-learning. It meant assuming responsibility for their learning; as one student writes, "This lab class is very unique because I have all the responsibility for myself. This class is not I can improve English but I can learn how to improve English for myself" (1.Q36.5).

\section{Notes}

${ }^{1}$ The Server is the local area network provider of applications. Students had access to e-mail, the UBC library system, the World Wide Web, and a word-processing program. In addition, students could pass in their work electronically by copying it from their floppy disk to their instructor's Drop Box, which was accessible on the Server. Similarly, instructors could make information available to students by placing copies in a Common file, which the students were free to access and copy for their records.

${ }^{2}$ For the second term the number of participants was reduced to 19 , either because they were accepted into regular courses on campus or because they were randomly assigned to other lab sections. An indexing system is used to determine whether students are permitted to register in regular university courses in the second term. The index comprises the students' TOEFL scores and first term marks in the sheltered courses. The lab classes, along with a lecture and a tutorial, were a component of sheltered courses.

${ }^{3}$ The Likert items had a 5-point scale ranging from Strongly disagree to Strongly agree with No opinion in the middle.

${ }^{4}$ Of the eight students selected for interviews, five were women and three were men. In the selection process, I attempted to create a balance between reflecting the number of women compared with men who volunteered for the study and the level of English as reflected by the range of TOEFL scores on entering the program. After the students were reassigned to classes for the second term, only four of these women and one man remained in the focus group.

${ }^{5}$ In order to maintain an audit trail (Lincoln \& Guba, 1985), comments have been coded to indicate their temporal and physical location in the data. For example, in the code 1.Q33.10, 1 indicates the questionnaire completed near the end of term 1,Q33 refers to the specific question, and 10 is the number assigned to replace the name of the participant.

${ }^{6}$ The participants in the study have been assigned pseudonyms. The discussion appears to rely heavily on the data from Emiko. The intention is to give the reader a more complete view of one case, Emiko's, while establishing that her case is not unique by drawing on the data from other cases. 


\section{The Author}

Garold L. Murray has been exploring learner autonomy in second-language-learning for 10 years. His work in this area includes experimenting with various classroom models, developing ESL curriculum for public schoolchildren, and giving numerous teacher in-service workshops. In addition, he has taught ESL at the middle school, high school, and tertiary levels. Having recently completed his doctorate at the University of British Columbia, he now teaches at Tokai University, Japan.

\section{References}

Cotterall, S. (1995). Readiness for autonomy: Investigating learner beliefs. System, 23(4), 195-205.

Dam, L. (1995). Learner autonomy: From theory to classroom practice. Dublin: Authentik.

Deci, E., \& Ryan, R. (1985). Intrinsic motivation and self-determination in human behavior. New York: Academic Press.

Dickinson, L. (1987). Self-instruction in language learning. Cambridge: Cambridge University Press.

Dickinson, L. (1993). Talking shop: Aspects of autonomous learning. ELT Journal, 47, 330-336.

Dickinson, L. (1995). Autonomy and motivation: A literature review. System, 23(4), 165-174.

Forsyth, A. (1990). Projet expérimental en anglais langue seconde, au Nouveau-Brunswick. Education Canada, 30(2), 23-29, 11.

Forsyth, A. (1993, November). Language acquisition management: ESL in Netw Brunswick, Canada. Paper presented at a conference organized by the Goethe Institute, Augsburg, Germany.

Forsyth, A. (1994). An automated self-directed multi-media program of modern language acquisition. In M. Buss \& C. Laurén (Eds.), Language immersion: Teaching and second language acquisition. Proceedings of the University of Vaasa Research Papers (pp. 60-72). Tutkimuksia No. 192, Linguistics 30.

Galloway, V., \& Labarca, A. (1990). From student to learner: Style, process and strategy. In D.W. Birckbichler (Ed.), New perspectives and new directions in foreign language education (pp. 111-158). Lincolnwood, IL: National Textbook Company.

Gremmo, M.-J., \& Riley, P. (1995). Autonomy, self-direction and self-access in language teaching and learning: The history of an idea. System, 23(2), 151-164.

Ho, J., \& Crookall, D. (1995). Breaking with Chinese cultural traditions: Learner autonomy in English language teaching. System, 23(4), 235-243.

Holec, H. (1981). Autonomy and foreign language learning. Oxford: Pergamon Press.

Holec, H. (1987). The learner as manager: Managing learning or managing to learn? In A. Wenden \& J. Rabin (Eds.), Learner strategies in language learning (pp. 145-157). London: Prentice-Hall.

Hoven, D. (1992). CALL in a language learning environment. CAELL Journal, 3(2), 19-27.

Jones, F. (1993). Beyond the fringe: A framework for assessing teach-yourself materials for $a b$ initio English-speaking learners. System, 21(4), 453-460.

Kenny, B. (1993a). For more autonomy. System, 21(4), 431-442.

Kenny, B. (1993b). Investigative research: How it changes learner status. TESOL Quarterly, 27, 217-231.

Knowles, M.S. (1975). Self-directed learning: A guide for learners and teachers. New York: Association Press.

Lincoln, Y., \& Guba, E. (1985). Naturalistic inquiry. Newbury Park, CA: Sage.

Little, D. (1990). Autonomy in language learning: Some theoretical and practical considerations. In I. Gathercole (Ed.), Autonomy in language learning (pp. 7-15). London:

Centre for Information on Language Teaching.

Little, D. (1991). Learner autonomy: Definitions, issues and problems. Dublin: Authentik. 
Little, D. (1995). Learning as dialogue: The dependence of learner autonomy on teacher autonomy. System, 23(2), 175-181.

Littlewood, W. (1993, August). Developing autonomy in the foreign language classroom. Paper presented at the 10th AILA Congress, Amsterdam, The Netherlands.

Stake, R. (1995). The art of case study research. Thousand Oaks, CA: Sage.

Tremblay, P. \& Gardner, R. (1995). Expanding the motivation construct in language learning. Modern Language Journal, 79, 505-518.

Victori, M., \& Lockhart, W. (1995). Enhancing metacognition in self-directed language learning. System, 23(2), 223-234.

Wenden, A. (1995). Learner training in context: A knowledge-based approach. System, 23(2), 183-194.

Yin, R. (1994). Case study research: Designs and methods (2nd ed.). Thousand Oaks, CA: Sage. 